\title{
Medidas lineares e angulares de animais da raça Quarto de Milha utilizados em uma prova de vaquejada*
}

\section{Linear and angular measurements of animals race Quarter Horse used in a proof vaquejada}

\author{
Anielle Cristina Alves Meneses, ${ }^{* *}$ Maria Dulcineia da Costa, ${ }^{* *}$ Suzana Maruch, ${ }^{* *}$ Paula Ramirez Moreira, ${ }^{* *}$ \\ Teotônio Martins Neto***
}

\begin{abstract}
Resumo
Objetivou-se com este trabalho avaliar as medidas lineares e angulares de animais da raça Quarto de Milha utilizados em prova de vaquejada. Foram mensurados 98 animais, sendo 70 machos e 28 fêmeas da raça Quarto de Milha. Foram coletadas as informações de 25 medidas lineares e 9 medidas angulares. As análises estatísticas foram realizadas utilizando-se o pacote estatístico SISVAR, sendo os dados submetidos a teste de SNK a $5 \%$ de probabilidade.Verificou-se diferença significativa $(P<0,05)$ entre os sexos apenas para as medidas lineares e angulares do comprimento do dorso-lombo, perímetro da canela posterior $\mathrm{e}$ para ângulo escapuloumeral. As fêmeas apresentaram maior dorso-lombo $(50,64$ e $47,31 \mathrm{~cm})$ e maior angulo escápulo-umeral (91,31 e 87,99 graus) enquanto os machos tiveram maior perímetro da canela $(20,26$ e $19,64 \mathrm{~cm})$. Os animais da raça Quarto de Milha utilizados em vaquejadas possuem medidas lineares similares entre os sexos. As conformações corporais nos equinos Quarto de Milha favorecem as exigências funcionais desse esporte.
\end{abstract}

Palavras-chave: cavalos de esporte, equinos, morfometria.

\begin{abstract}
The of work aims to evaluate the linear and angular measurements of Quarter Horse breed animals were in proof vaquejada. Measured were 98 animals being 70 males and 28 females of the breed Quarter Horse. Were collected the information of 25 linear and measures 9 measures angular. The statistical analyses were conducted using the statistical package SISVAR, being the data submitted by SNK test at $5 \%$ of probability. There was significant difference $(P<0.05)$ between the sexes only for linear and angular measurements of length the back-loin, rear perimeter of cinnamon and scapulohumeral angle. Females showed greater dorsal rib (50.64 and $47,31 \mathrm{~cm})$ and greater angle scapulohumeral (91.31 and 87.99 degrees) while males had higher perimeter of cinnamon $(20.26$ and $19.64 \mathrm{~cm}$ ). The animals of the Quarter Horse used in vaquejada have similar linear measurements between the sexes. The body conformations in Quarter Horse favor the functional demands of the sport.
\end{abstract}

Keywords: sport horses. equine, morphometric measuraments.

\section{Introdução}

Caracterizada por sua versatilidade, a raça equina Quarto de Milha possui habilidade para várias modalidades esportivas (vinte e duas, segundo a Associação Brasileira de Criadores de Cavalo Quarto de Milha - (ABQM) como rédeas, apartação, conformação, corrida, vaquejada etc.). Apesar desta grande variedade de atividades, a seleção de características relacionadas com a robustez e velocidade dos animais predominou.

O Quarto de Milha é adaptável a qualquer situação, transformando-se em instrumento de força, transporte e difícil de ser derrotado em provas equestres, além de melhorador de plantel (ABQM, 2013).

Nas provas de vaquejada, os cavalos são extremamente exigidos, realizam esforço físico de alta intensidade, mas de curta duração, o que reflete em rápida largada, mudanças de direção e paradas abruptas, além de exigir elevada força física durante a derrubada do boi, sendo que alguns cavalos chegam a disputar várias provas em uma mesma competição, todos os fins de semana (Xavier, 2002).

A qualidade do movimento, atividade desenvolvida e caracterização racial são fatores relacionados com a conformação dos equinos, que pode ser mensurada por meio de medidas lineares e angulares (Santiago et al., 2012). De acordo com Nascimento (1999), o padrão racial busca qualidades morfozootécnicas que visam equilibrar, compensar e harmonizar as partes, bem como atingir, dentro da prática zootécnica de seleção, a qualidade funcional. Da mesma forma, a proporção e as relações entre segmentos corporais são tão importantes quanto os valores de mensurações isolados, pois implicam diretamente a direção, amplitude, força e estabilidade dos movimentos executados (Santiago et al., 2012). Portanto, objetivou-se através deste trabalho avaliar as medidas lineares e angulares em animais da raça Quarto de Milha participantes de vaquejada.

\footnotetext{
*Recebido em 16 de dezembro de 2013 e aceito em 24 de fevereiro de 2014.

${ }^{* *}$ Programa de Pós-graduação em Zootecnia - Unimontes, Janaúba - MG. Email: aninhameneses88@hotmail.com, bolsitas Fapemig.

${ }^{* * *}$ Curso de Zootecnia - UNIMONTES, Janaúba - MG, bolsistas CNPQ
} 


\section{Material e métodos}

Foram coletadas 25 medidas lineares e 9 medidas angulares de 98 animais, sendo 70 machos e 28 fêmeas da raça Quarto de Milha puros e mestiços com idade variando de 2,5 a 12 anos participantes da Vaquejada do Grotão da Saudade no município de Verdelândia, Norte de Minas Gerais, no período de 21 a 25 de maio de 2013. As medidas foram obtidas utilizando-se de um hipômetro, duas fitas métricas e um artrogoniômetro. As mensurações foram realizadas com os animais em estação forçada seguindo a metodologia utilizada por (Santiago, 2013).

As medidas avaliadas foram: altura na cernelha, altura na garupa, altura no dorso, altura do costado, cintura pélvica, comprimento da cabeça, comprimento do pescoço, comprimento do dorso-lombo, comprimento da garupa, comprimento da espádua, comprimento do corpo, comprimento do antebraço, comprimento da quartela, comprimento da coxa, comprimento da perna, comprimento da canela anterior, comprimento da canela posterior, comprimento do braço, largura da cabeça, largura da garupa, largura do peito, perímetro torácico, perímetro da canela anterior, perímetro da canela posterior, perímetro pélvico, ângulo escapulo-solo, ângulo escapulo-umeral, ângulo úmero-radial, ângulo metacarpo-falangeano, ângulo pelve-solo, ângulo pelve-femoral, ângulo fêmur-tíbio-patelar, ângulo tíbiotarso-metatarsiano, ângulo metacarpo-falangeano posterior.

As análises estatísticas foram realizadas utilizando-se o pacote estatístico SISVAR, descrito por Ferreira (2000), sendo os dados submetidos ao teste de SNK a $5 \%$ de probabilidade.

Os procedimentos realizados nesse experimento foram aprovados pelo Comitê de Ética para Experimentação Animal da Universidade Estadual de Montes Claros (protocolo no. 068/2013).

\section{Resultados e discussão}

Verificou-se diferença significativa $(P<0,05)$ entre os sexos apenas para as medidas lineares comprimento do dorso-lombo e o perímetro da canela posterior de acordo com a Tabela1. As fêmeas apresentaram comprimento do dorso-lombo superior aos machos.

Os valores encontrados foram superiores ao observado por Cabral et al. (2004) e Miserani et al. (2002) para potras e potros de 12 meses em animais Mangalarga Machador e Pantaneiro, respectivamente, e foram inferiores aos encontrados por Berbari Neto (2005) em animais Campolina. Já as fêmeas Quarto de Milha tiveram comprimento do dorso-lombo superior em animais Mangalarga Machador (Santiago, 2013). Santos (1981) afirmou que, para um cavalo ser bem proporcionado, é necessario que o dorso-lombo seja relativamente curto, enquanto a espádua e a garupa sejam longas. O dorso curto é geralmente forte, mas em um cavalo de porte mais elevado, um dorso mais longo pode conferir maior comprimento dos músculos, resultando em passadas mais amplas durante o galope. Por esta razão, em algumas linhagens de Puro- Sangue Inglês (PSI), cujos andamentos são necessariamente alongados e muito velozes, o dorso mais longo é favorável (Nascimento, 1999). Sendo assim, em animais Quarto de Milha o maior comprimento do dorso-lombo pode estar relacionado com a função como animal de esporte de velocidade, e nas fêmeas a superioridade se deve à maior musculatura e arqueamento das costelas favorecendo a função reprodutiva.

Tabela 1: Médias e coeficiente de variação (CV) das medidas lineares de animais da raça Quarto de Milha utilizados em vaquejada de acordo com o sexo

\begin{tabular}{|c|c|c|c|c|}
\hline \multirow{2}{*}{$\begin{array}{l}\text { Medida Linear } \\
\quad(\mathrm{cm})\end{array}$} & \multicolumn{2}{|c|}{ Sexo } & \multirow{2}{*}{$\begin{array}{l}\text { Média Geral } \\
(\mathrm{cm})\end{array}$} & \multirow[t]{2}{*}{$\mathrm{CV}(\%)$} \\
\hline & Fêmea & Macho & & \\
\hline antbC & $38,03^{a}$ & $38,51^{\mathrm{a}}$ & $38,37 \pm 0.02$ & 4,98 \\
\hline caantC & $18,93^{a}$ & $19,20^{\mathrm{a}}$ & $19.12 \pm 0.01$ & 5,62 \\
\hline quaantC & $10,96^{a}$ & $12,34^{a}$ & $11,66 \pm 0.11$ & 9,77 \\
\hline caposC & $24,04^{a}$ & $23,93^{a}$ & $23,96 \pm 0.02$ & 6,31 \\
\hline quaposC & $10,25^{\mathrm{a}}$ & $10,40^{\mathrm{a}}$ & $21,46 \pm 1.10$ & 6,08 \\
\hline cabC & $55,25^{\mathrm{a}}$ & $55,24^{a}$ & $55,24 \pm 0.03$ & 5,59 \\
\hline pescC & $60,25^{\mathrm{a}}$ & $61,26^{a}$ & $60,96 \pm 0.04$ & 7,32 \\
\hline dorC & $50,64^{a}$ & $47,31^{b}$ & $48,26 \pm 0.04$ & 7,29 \\
\hline garC & $49,54^{a}$ & $50,64^{a}$ & $50,33 \pm 0.03$ & 6,45 \\
\hline espC & $54,29^{a}$ & $54,88^{a}$ & $54,51 \pm 0.03$ & 4,89 \\
\hline brcC & $32,64^{a}$ & $33,76^{a}$ & $33,39 \pm 0.03$ & 10,41 \\
\hline $\mathrm{cxC}$ & $42,75^{a}$ & $41,50^{\mathrm{a}}$ & $42,94 \pm 0.10$ & 7,84 \\
\hline $\mathrm{cpC}$ & $149,60^{a}$ & $149,34^{a}$ & $149,52 \pm 0.04$ & 2,70 \\
\hline $\mathrm{pnC}$ & $49,50^{\mathrm{a}}$ & $48,63^{a}$ & $48,82 \pm 0.02$ & 5,01 \\
\hline perpvP & $176,71^{a}$ & $177,49^{a}$ & $176,24 \pm 0.12$ & 3,73 \\
\hline $\mathrm{txP}$ & $183,50^{a}$ & $182,10^{a}$ & $182,50 \pm 0.11$ & 6,02 \\
\hline caantP & $19,64^{b}$ & $20,26^{a}$ & $20,08 \pm 0.02$ & 3,73 \\
\hline caposP & $22,25^{\mathrm{a}}$ & $22,61^{a}$ & $22,51 \pm 0.01$ & 4,35 \\
\hline cerAL & $147,89^{a}$ & $147,72^{a}$ & $147,80 \pm 0.04$ & 2,51 \\
\hline dorAL & $141,57^{a}$ & $141,53^{a}$ & $141,58 \pm 0.04$ & 2,67 \\
\hline $\cos A L$ & $60,48^{a}$ & $59,81^{a}$ & $59,98 \pm 0.03$ & 4,69 \\
\hline cpelAL & $49,25^{a}$ & $49,53^{a}$ & $49,91 \pm 0.04$ & 12,66 \\
\hline garAL & $150,00^{\mathrm{a}}$ & $149,94^{\mathrm{a}}$ & $149,16 \pm 0.09$ & 2,13 \\
\hline cabL & $21,75^{\mathrm{a}}$ & $22,17^{a}$ & $22,00 \pm 0.01$ & 5,54 \\
\hline peiL & $44,39^{a}$ & $44,42^{\mathrm{a}}$ & $44,41 \pm 0.02$ & 5,46 \\
\hline garL & $52,32^{a}$ & $51,47^{a}$ & $51,77 \pm 0.02$ & 4,43 \\
\hline
\end{tabular}

Letras distintas na mesma linha indicam diferença significativa pelo teste SNK $(p<0,05)$.

antbC -comprimento antebraço, caantC- comprimento canela anterior, quaantC- comprimento quartela anterior, caposC- comprimento canela posterior, quaposC- comprimento quartela posterior, cabC- comprimento cabeça, pescC- comprimento pescoço, dorC- comprimento dorso, garCcomprimento garupa, espC- comprimento espádua, brçC- comprimento braço, cxC-comprimento coxa, cpC- comprimento corpo, pnC- comprimento perna, perpvP- perímetro pélvico, txP- perímetro tórax, caantP- perímetro canela anterior, caposP- perímetro canela posterior, cerAL- altura cernelha, dorALaltura dorso, cosAL- altura costado, pelAL- altura pélvica(bainha), garALaltura garupa, cabL- largura cabeca, peiL- largura peito, garL- largura garupa

O perímetro da canela está relacionado com a qualidade óssea do esqueleto e com a funcionalidade da região anatômica, determinando, juntamente com o perímetro torácico, a capacidade de carga do animal (Berbari Neto; 2005). O perímetro da canela anterior do macho foi superior ao da fêmea. Esta diferença pode ser explicada pelo dimorfismo sexual. Além disso, os machos são mais utilizados nas atividades esportivas 
e há necessidade de melhor estrutura óssea por ocasião do apoio dos bípedes anteriores do animal no solo quando, cerca de 60 a $65 \%$ do peso do cavalo e suportado pelos membros anteriores (Jones, 1987).

Os valores nesse trabalho foram superiores aos observados por Miserani et al. (2002) e Berbari Neto (2005) em animais Pantaneiro e Campolina, respectivamente.

O comprimento do antebraço foi inferior ao encontrado por Santiago (2013) em animais Mangalarga Machador. Direção vertical do antebraço proporciona bons aprumos, com boa base de sustentação. Antebraço curto tem como resultado passadas curtas com maior elevação dos membros. Consequentemente requer maior número de movimentos no mesmo intervalo de tempo e o cavalo trabalha mais, movendo mais rapidamente os membros anteriores para manter a velocidade, apesar de atingir a fadiga mais rapidamente (Camargo e Chieffi, 1971). Nos animais Quarto de Milha o antebraço mais curto pode estar relacionado com a necessidade de manter velocidade mais elevada nas provas esportivas.

Comprimento do braço foi superior ao encontrado por Santiago (2013) em animais Mangalaga Machador. Um braço longo é importante tanto nos cavalos de corrida, como nos de sela e tração. Nos dois primeiros para permitir movimentos amplos e no terceiro para oferecer maior base de inserção aos músculos (Fontes, 1954 e Nascimento, 1999). No Quarto de Milha o comprimento do braço apresentando-se maior do que o Mangalarga Mangalarga pode ser devido a exigência do animal na prova de vaquejada para maior passada e velocidade onde o Mangalarga Marchador possui passadas menores por ser animal de marcha e não de velocidade.

Dentre as regiões constituintes do corpo do cavalo, as espáduas talvez sejam as mais críticas, devido à influência positiva ou negativa que exercem sobre as diversas fases da locomoção, estando intimamente relacionadas com a cernelha, pescoço, tórax e dorso (Jones, 1987). Os animais Quarto de Milha avaliados tiveram comprimento da espádua superiores aos encontrados por Miserani et al. (2002) e Santiago (2013) em animais Pantaneiro e Mangalarga Marchador e inferior aos animais Campolina observado por (Berbari Neto, 2005). De acordo com Inglês et al. (2004), as espáduas devem ser longas, oblíquas, bem definidas, musculosas e de amplos movimentos. Esta morfologia favorece a amplitude das passadas dos membros anteriores. Espáduas curtas restringem a amplitude da passada. Um bom comprimento das espáduas está associado também a uma boa altura de costados e projeção de cernelha (Vale, 1984). A espádua oblíqua absorve melhor o impacto gerado pelo contato do casco com o solo, resultando em maior amortecimento e suavidade durante a locomoção (Jones, 1987).

O comprimento da canela anterior e posterior foram inferiores ao encontrado por Santiago(2013) e Godoi (2013) para animais Mangalarga Marchador e potros de 36 a 39 meses Brasileiro de Hipismo, respectivamente. Segundo Jones (1987), a canela tem menos necessidade de ser mais comprida que o antebraço quando se busca velocidade. Como no joelho, a área da canela deve ter pouca deposição de tecido adiposo e conectivo, pois ambos, quando em excesso, tendem a interferir negativamente no movimento.

O comprimento da quartela anterior e posterior foram inferiores aos valores encontrados por Lage (2009), Santiago (2013), e
Godoi (2013) animais Margalarga Machador e potros de 36 a 39 meses Brasileiro de Hipismo. Quartelas relativamente longas e oblíquas dispersam mais facilmente as forças da locomoção. Porém, quando excessivamente alongadas, necessitam de maior força para sua sustentação, sobrecarregando ligamentos e os sesamoides, enquanto quartelas muito curtas e verticais têm menor habilidade para absorver os impactos, resultando em andamentos ásperos (Jones, 1987).

O comprimento da cabeça foi inferior ao encontrado por Miserani et al. (2002), Berbari Neto (2005) e Santiago (2013), e em animais Pantaneiro, Campolina e Mangalarga Marchador, respectivamente. Por outro lado, a largura da cabeça foi superior à encontrada por esses autores. O comprimento, largura e forma da cabeça são itens importantes por conferirem expressão racial aos animais, além de demonstrar feminilidade na fêmea (Gonçalves et al., 2012). Em relação ao comprimento, cabeça mais comprida pesa à mão do equitador, desloca o centro de gravidade para frente e sobrecarrega os membros torácicos, tornando o animal sujeito a tropeçar com mais facilidade. A cabeça curta e proporcional constitui qualidade e beleza estética, principalmente quando ligada a um pescoço longo, pois é fácil de ser conduzida e alivia os membros torácicos (Fontes, 1954; Nascimento, 1999 e Cid, 1999). Segundo Vale (1984), a cabeça deve ser de comprimento mediano. Se excessivamente curta, torna-se móvel e facilita o movimento dos anteriores, porém ao deslocar o centro de gravidade para trás, predisporá a movimentos improgressivos. No Quarto de Milha se apresentando cabeça menor facilita os movimentos de rotação do animal e sua parada brusca, exigência do esporte da vaquejada.

O comprimento do pescoço foi inferior ao encontrado por Berbari Neto (2005), Santiago (2013), e Godoi (2013) para animais Campolina, Mangalarga Marchador e Brasileiro Hipismo e superior ao encontrado Miserani (2002) em animais Pantaneiro.

Um cavalo de pescoço mais curto, geralmente também apresenta espáduas curtas, terá um deslocamento curto dos membros anteriores, sendo menos apto para utilizar o membro anterior com versatilidade. Nos animais de pescoço excessivamente longo, os músculos tendem ao subdesenvolvimento, estando, desta forma, mais propensos à fadiga (Andrade, 2002).

Comprimento do corpo foi inferior ao encontrado por Berbari Neto(2005), Godoi (2013), Santiago (2013) e Donofre (2014) em animais Campolina, Brasileiro de Hipismo de 36 a 39 meses, Mangalarga Marchador e Quarto de Milha de prova de três tambores e superior ao encontrado por Miserani et al. (2002) em animais Pantaneiro. Os animais Quarto de Milha nesse trabalho se apresentaram curto aos comparados na literatura, mas com bastante musculatura de acordo com o padrão da raça.

Comprimento de perna foi superior ao encontrado por Santiago (2013) e Godoi (2013) em animais Mangalarga Marchador e Brasileiro Hipismo ao 36 a 39 meses. Pernas curtas resultam em limitação da velocidade, exigindo esforço em dobro e reduzindo o tempo de fadiga (Nascimento, 1999).

A inclinação da perna está diretamente relacionada com a inclinação da garupa e inversamente proporcional à abertura do ângulo do jarrete. Como regra geral, perna mais vertical é favorável à velocidade e mais oblíqua à força (Nascimento,1999). Nos animais Quarto de Milha o comprimento de perna é longa, explicando assim um animal de velocidade. 
Comprimento de coxa foi superior ao encontrado por Santiago (2013), animais Mangalarga Marchador e inferior ao encontrado por Donofre (2014) em animais Quarto de Milha de prova de três tambores. O comprimento e a inclinação da coxa são importantes para o comprimento da passada. Segundo Nascimento (1999), o ideal é que a coxa e a perna apresentem comprimento semelhante, resultando em um jarrete relativamente baixo. Para Nascimento (1999), se a coxa for muito curta, o jarrete será alto e os músculos da coxa curtos, inviabilizando uma passada ampla. A coxa é mais verticalizada no PSI e mais oblíqua no cavalo de tração. Aliás, aquela direção é favorável à velocidade e esta à força (Nascimento, 1999).

O comprimento da garupa foi inferior ao encontrado por Berbari Neto (2005), Santiago (2013), para animais Campolina e Mangalarga Marchador, e superior ao encontrado por Miserani et al. (2002) em animais Pantaneiro enquanto na largura e altura da garupa foi inverso ao encontrado por esses autores. Garupas compridas estão associadas a músculos longos, capazes de amplas contrações, facilitando a propulsão. Esta característica é especialmente desejável nos cavalos de corrida, salto e também nos marchadores nacionais. Uma garupa curta é tolerada somente nos cavalos de tração, porém nestes a falta de comprimento deve ser compensada por maior desenvolvimento muscular (Fontes, 1954 e Nascimento, 1999). A garupa larga é desejável, desde que não prejudique o deslocamento dos membros, especialmente nos cavalos de salto, tração e na raça Quarto de Milha. Quando estreita, indica fraqueza, constituindo defeito absoluto (Fontes, 1954 e Nascimento, 1999). Nos animais Quarto de Milha comparado com a literatura de outras raças, a garupa apresenta menor comprimento e maior largura, o que favorece melhores propulsões e impulsão na arrancada do animal.

Perímetro pélvico e altura pélvica nos animais Quarto de Milha é uma região de grande musculatura, obtendo maior força para impulsão na arrancada do animal. Perímetro do tórax foi superior ao encontrado por Miserani et al. (2002) e Santiago(2013) em animais Pantaneiro e Mangalarga Marchador e valores iguais encontrados por Berbari Neto(2005) em animais Campolina. A capacidade torácica é medida pela profundidade e quanto maior for a amplitude do tórax e o arqueamento das costelas, maior será a área disponível para abrigar todo o sistema cardiorrespiratório do cavalo, favorecendo seu melhor funcionamento. A capacidade torácica é medida pela profundidade e não pela largura do tórax. As costelas, sendo longas e bem arqueadas, indicam um perímetro torácico desejável (Inglês et al., 2004). No Quarto de Milha esse perímetro é explicado devido ao maior arqueamento das costelas, e na vaquejada o animal gasta muita energia em pouco tempo, aumentando suas funções respiratórias.

O perímetro da canela posterior foi superior ao encontrado por Kurtz Filho et al. (2007) e Lage et al.(2009) para macho e fêmea em animais Crioulos e Mangalarga Marchador e valor inferior ao encontrado por Cabral et al. (2004) em animais Mangalarga Marchador aos 12 meses.). O perímetro canela deve ser largo para que haja boa implantação dos tendões, garantindo bom desenvolvimento muscular do aparato locomotor (Vale, $1984 \mathrm{e}$ Barbosa, 1993). Nos animais Quarto de Milha a canela posterior é mais larga e mais longa que as anteriores para permitir voltas rápidas e paradas bruscas.

A altura da cernelha foi inferior ao encontrado por Berbari Neto (2005), Santiago (2013) em animais Campolina e Mangalarga Marchador e valores superiores aos encontrados por Miserani et al. (2002) e Kurtz Filho et al. (2007) em animais Pantaneiros e para macho e fêmeas em animais Crioulo. Em animais Quarto de Milha nesse estudo a altura da cernelha apresentou $0,67 \%$ menor que o exigido pelo padrão da raça.

A altura do dorso foi superior à encontrada por Miserani (2002) e Santiago(2013) em animais Pantaneiro e Mangalarga Marchador e valores inferiores aos observados por Berbari Neto(2005) em animais Campolina.

A altura do costado foi inferior à encontrada por Cabral (2004), Berbari Neto (2005) e Santiago (2013), em animais Mangalarga Marchador e Campolina e valores inferiores aos observados por Miserani et al. (2002) em animais Pantaneiro.

As proporções do peito, tanto na profundidade quanto na largura, são extremamente importantes, conferindo resistência ao equino (Jones, 1987). Região peitoral moderadamente larga e bem musculada indica pulmões, tórax e músculos bem desenvolvidos (Nascimento, 1999). Nos animais Quarto de milha, a largura de peito foi superior aos valores encontrados na literatura para outras raças (Miserani, 2002; Cabral et al., 2004; Berbari Neto, 2005 e Santiago, 2013 e) se justifica pela maior necessidade de oxigenação em razão do maior esforço praticado nas várias provas esportivas desempenhadas pela raça.

O ângulo escapulo-umeral é importante para o impulso. Escápulas com maior inclinação apresentam maior área para inserção muscular e possibilitam maior flexibilidade e amplitude dos movimentos dos membros torácicos, além de incrementar os deslocamentos em altura desses. A verticalização da escápula associada a maior ângulo escapulo-umeral dará menor avanço e consequentemente menor comprimento da passada, aliado à menor flexibilidade articular e concomitante redução do amortecimento dos atritos verticais (Sierra et al., 1998). Verificouse diferença significativa $(P<0,05)$ entre os sexos apenas para a medida angular escapulo-umeral (Tabela 2). O ângulo escapuloumeral nos machos pode estar associado à maior capacidade de impulsão. Os valores observados neste estudo foram inferiores aos encontrados por Santiago (2013) em animais Mangalarga Machador, mais superior aos de Ramires (2013) em animais da raça Quarto de Milha em prova de laço.

Tabela 2: Médias e Coeficiente de variação (CV) das angulações de animais da raça Quarto de Milha utilizados em vaquejada de acordo com o sexo.

\begin{tabular}{crrrr}
\hline \multirow{2}{*}{ Medidas ângulos } & \multicolumn{2}{c}{ Sexo } & Média Geral & CV(\%) \\
\cline { 2 - 3 } & Fêmea & Macho & & \\
\hline esA & $62,86^{a}$ & $61,70^{a}$ & $62,04 \pm 5,03$ & 8,11 \\
euA & $91,31^{a}$ & $87,99^{\mathrm{b}}$ & $89,18 \pm 5,60$ & 6,22 \\
urA & $112,83^{\mathrm{a}}$ & $111,84^{\mathrm{a}}$ & $112,48 \pm 7,32$ & 5,23 \\
mfA & $139,28^{\mathrm{a}}$ & $140,64^{\mathrm{a}}$ & $139,91 \pm 8,13$ & 5,14 \\
psA & $29,14^{\mathrm{a}}$ & $29,29^{\mathrm{a}}$ & $28,79 \pm 5,02$ & 23,48 \\
pfA & $70,59^{\mathrm{a}}$ & $74,96^{\mathrm{a}}$ & $73,17 \pm 11,02$ & 21,52 \\
ftpA & $59,14^{\mathrm{a}}$ & $61,87^{\mathrm{a}}$ & $84,50 \pm 9,58$ & 22,32 \\
ttmA & $145,52^{\mathrm{a}}$ & $145,88^{\mathrm{a}}$ & $145,90 \pm 6,60$ & 4,93 \\
mfpA & $146,79^{\mathrm{a}}$ & $148,59^{\mathrm{a}}$ & $148,01 \pm 6,82$ & 4,11 \\
\hline
\end{tabular}

Letras distintas na mesma linha indicam diferença significativa pelo teste SK $(p<0,05)$.

esA-escapulo-solo; euA-escapulo-umeral; urA-úmero-radial; mfA-metacarpofalangeano; psA-pelve-solo; pfA-pelve-femur; ftpa-fêmur-tíbio-patelar; ttmAtíbio-tarso-metartasiano; mfpA-metacarpo-falangeano-posterior 
O ângulo escapulo-solo foi superior ao encontrado por Ramires et al. (2013) e Santiago (2013) em animais Quarto de Milha em prova de laço e Mangalarga Marchador, respectivamente. De acordo com Camargo e Chieffi (1971), a variação do ângulo escapulo-solo pode ser de 45 a 70 graus, sendo de 45 a 55 graus para animais de tração e sela, e acima de 55 graus nos equinos de corrida, onde uma boa angulação influencia no equilíbrio do animal, pois quanto menor a angulação, menor a passada. Isto sugere que os animais da raça Quarto de Milha utilizados em vaquejada podem ser classificados como animais de corrida.

O ângulo umerorradial e metacarpofalangeano foi inferior aos ângulos observados por Lage et al. (2009), Santiago (2013) e Ramires et al. (2013) em animais da raça Mangalarga Marchador e fêmea e macho Quarto de Milha de laço, mas para o ângulo metacarpo-falangeano foi superior. De acordo com Harris (1993) a inclinação da espádua determina a amplitude do movimento e o comprimento da passada. Uma espádua inclinada permite um movimento avante e para cima, característica importante, principalmente, nos cavalos de salto. Já uma espádua pouca inclinada restringe a amplitude do movimento e o comprimento da passada.

O ângulo pelve-solo foi inferior ao observado por Lage et al. (2009) e Ramires (2013), em animais Mangalarga Marchador e Quarto de Milha de laço e superior ao observado por Santiago (2013) em animais Mangalarga Marchador. Segundo Camargo e Chieffi (1971), garupa inclinada, quando a orientação apresentar ângulos de 25 a 30 graus, acarreta inserção menos favorável dos músculos glúteos e ísquio-tibiais, prejudicando a extensão. Entretanto, há potencialização do impulso, quando o menor comprimento daqueles músculos é compensado por seu maior volume. Esta pode ser a explicação para a maior propulsão no Quarto de Milha com maior desenvolvimento dos glúteos.

O ângulo pelve-femur foi inferior ao observado por Nascimento (1999), Lage et al. (2009) e Santiago(2013), e superior ao observado por Ramires et al. (2013) em animais Quarto de Milha de laço. No quarto de milha a coxa é mais inclinada, o que vai provocar maior propulsão nos membros posteriores e consequentemente maior explosão para arrancada na corrida.

O ângulo fêmur-tíbio-patelar foi inferior aos valores observados por Nascimento (1999), ABCCMM (2005), Lage et al. (2009) e Ramires et al. (2013), em animais Mangalarga Marchador e Quarto de Milha de laço. Isso ocorre, pois quanto menor o ângulo fêmur-tíbio-patelar, melhor flexão dos jarretes, o que facilita a maior propulsão dos membros pélvicos e melhor flexibilidade para as paradas brusca dos animais Quarto de Milha.

O ângulo tíbio-tarso-metartasiano foi inferior aos animais Mangalarga Marchador e Quarto de Milha de laço observado por Nascimento (1999), ABCCMM (2005), Lage et al. (2009) e Ramires et al. (2013). De acordo com Nascimento (1999) o ângulo do jarrete oscila entre 140 e 160 graus, sendo maior nos cavalos de corrida, marchadores e Quarto de Milha e menor no tipo tração. Quando fechado, ou seja, inferior a 140 graus, o ângulo tíbio-tarso-metatarsiano é impróprio tanto para cavalo de corrida como para os marchadores, e tolerável nos tipos tração leve e pesada.

O ângulo metatarso-falangeano foi superior ao metacarpofalageano. Isso possivelmente ocorre para favorecer a propulsão pelos membros posteriores quando da partida e nos membros anteriores, suportar o maior peso do animal Quarto de Milha.

\section{Conclusões}

Os animais da raça Quarto de Milha utilizados em vaquejadas possuem medidas lineares e angulares similares entre os sexos, exceto para o comprimento do dorso-lombo, perímetro da canela posterior e para ângulo escapulo-umeral.

As conformações corporais nos equinos Quarto de Milha favorecem as exigências funcionais desse esporte.

Existe variabilidade genética entre e dentro de raça para as angulações em equinos reforçando a associação destas regiões anatômicas com a função desempenhada pelo animal.

\section{Agradecimentos}

À FAPEMIG E CAPES pelo apoio financeiro e aos criadores e competidores pela paciência e disponibilidade dos animais.

\section{Referências}

ABQM. Associação brasileira dos criadores de cavalos Quarto de Milha [2013]. Disponível em: <http://portalabqm.com.br/index. php?option=com_content $\&$ view=article\&id=234\%3Aqualidade-daraca\&catid=28\%3̈A-raca\&ltemid=3 > Acesso em: 22 nov. 2013.

ABQM. Anuário Quarto de Milha. Associação Brasileira dos Criadores de Cavalos Quarto de Milha, 2002, p. 25.

ASSOCIAÇÃO BRASILEIRA DOS CRIADORES DO CAVALO MANGALARGA MARCHADOR - ABCCMM. Primeiro relatório do projeto de avaliação morfométrica em cavalos da raça Mangalarga Marchador (“True Type") da ABCCMM. Belo Horizonte, 2005.

ANDRADE, L. S. Manual do julgamento de equinos. Conformação versus Função. $1^{a}$ ed. Belo Horizonte: Equicenter Publicações, 2002, p. 114.

BARBOSA, C.G. Estudo morfométrico na raça Mangalarga Marchador - Uma abordagem multivariada. 1993. $77 \mathrm{f}$. Dissertação (Mestrado em Zootecnia) - Escola de Veterinária Universidade Federal de Minas Gerais, Belo Horizonte, 1993.
BERBARI NETO, F. Evolução de medidas lineares e avaliação de índices morfométricos em garanhões da raça Campolina. 2005. 90 f. Dissertação (Mestrado em Zootecnia) - Universidade Estadual do Norte Fluminense, Campos dos Goytacazes, Rio de Janeiro, 2005.

CABRAL, G.C.; ALMEIDA, F.Q.; QUIRINO, C.R. Avaliação morfométrica de equinos da raça Mangalarga Marchador: índices de conformação e proporções corporais. Revista Brasileira de Zootecnia, v. 33, n. 6, p.1798-1805, 2004.

CAMARGO, M.X.; CHIEFFI, A. Ezoognózia. São Paulo: Instituto de Zootecnia, 1971, p. 320.

CID, P.S. Hipologia. O Exterior do Cavalo. MG editores, 1999.

DONOFRE, A.C; FILHO, J.N.P.P; FERREIRA, I.E.P. et. al. Equilíbrio de cavalos da raça Quarto de Milha participantes da modalidade de três tambores por meio de proporções corporais. Ciência Rural, Santa Maria, v. 44, n. 2, p. 327-332, 2014.

FERREIRA, D. F. SISVAR. Sistema de análise de variância para dados balanceados. Lavras: UFLA, 2000. 
FONTES, L.R. Exterior, raças e julgamento dos animais domésticos. Belo orizonte: Universidade Rural do Estado de Minas Gerais, 1954, p. 126.

GODOI et al. Morfologia de potros da raça Brasileiro de Hipismo. Ciência Rural, Santa Maria, v. 43, n. 4, p. 736-742, 2013.

GONÇALVES, R.W.; COSTA, M.D.; REZENDE, A.S.C.; ROCHA JÚNIOR, V.R. et al. Efeito da endogamia sobre características morfométricas em cavalos da raçaMangalarga Marchador.

Arquivo Brasileiro Meicina Veterinaria e Zootecnia, v. 64, n. 2, p. 419-426, 2012.

HARRIS, S.E. Horse gaits, balance and movement. New York: Howell Book House, 1993, p.178.

INGLÊS F.P.L.D., VIANNA S.A.B.; PROCÓPIO A.M. Padrão Racial Comentado do Cavalo Campolina. Belo Horizonte. Associação Brasileira dos Criadores do Cavalo Campolina, 2004.

JONES, W.E. Genética e Criação de Cavalos. São Paulo: Roca, 1987. p. 666.

KURTZ FILHO, M.; LÖF, H.K. Biometria de equinos da raça Crioula no Brasil. Archives of Veterinary Science v.12, n.1, p. 4751, 2007.

LAGE, M.C.G.R.; BERGMANN, J.A.G.; PROCÓPIO, A.M. et al. Associação entre medidas lineares e angulares de equinos da raça Mangalarga Marchador. Arquivo Brasileiro Medicina Veterinária Zootecnia, v. 61, n. 4, p. 968-979, 2009.

MISERANI, M.G.; MCMANUS, C., SANTOS, S. A. et al. Avaliação dos Fatores que Influem nas Medidas Lineares do Cavalo Pantaneiro. Revista Brasileira Zootecnia, v . 31, p. 335-341, 2002.
NASCIMENTO, J.F. Mangalarga marchador: tratado morfofuncional. Belo Horizonte: ABCCMM, 1999, p.577.

RAMIRES, G.G; REZENDE, M.P.G. ABREU, U. G.P. et al. Medidas angulares de equinos da raça quarto de milha utilizados em provas de laço comprido. 6. Simposio Recursos Naturais e Socioeconômico do Pantanal. Corumba. Mato Grosoo do sul, 2013.

SANTIAGO, J. M.; FONSECA, M.G.; ABRANTES, R.G.P. et al. Correlações fenotípicas entre medidas morfométricas lineares e angulares de equinos da raça Mangalarga Marchador. In: REUNIÃO ANUAL DA SOCIEDADE BRASILEIRA DE ZOOTECNIA, 49., 2012, Brasília. Anais...Brasília: Sociedade Brasileira de Zootecnia, 2012.

SANTIAGO, J.M. Caracterização morfométrica da raça Mangalarga Marchador. 2013, 110 f. Tese (Doutorado em Zootecnia) - Escola de Veterinária - Universidade Federal de Minas Gerais, Belo Horizonte, 2013.

SANTOS, R.F. O cavalo de sela brasileiro e outros equídeos. Botucatu: Editora Varela, 1981.p. 288.

SIERRA, G.F.; VALERA, M.; ALCALÁ, A.M. La valoración morfológica lineal em El caballo de Pura Raza Española. Avances en Alimentación y Mejora animal, v. 38, p.7-10, 1998.

XAVIER, I.L.G.de S. Detecção de enfermidades do aparelho locomotor através do exame físico em eqüinos de vaquejada. Monografia (Graduação em Medicina Veterinária) - Escola Superior de Agricultura de Mossoró, Mossoró, 2002. 